Correction

\title{
Correction: Xie et al. Distributed Attitude Synchronization for Spacecraft Formation Flying via Event-Triggered Control. Appl. Sci. 2021, 11, 6299
}

\author{
Xiong Xie $\mathbb{D}^{\circ}$, Tao Sheng * and Liang He
}

check for updates

Citation: Xie, X.; Sheng, T.; He, L. Correction: Xie et al. Distributed Attitude Synchronization for Spacecraft Formation Flying via Event-Triggered Control. Appl. Sci. 2021, 11, 6299. Appl. Sci. 2022, 12 , 2352. https://doi.org/10.3390/ app12052352

Received: 26 January 2022 Accepted: 16 February 2022 Published: 24 February 2022

Publisher's Note: MDPI stays neutral with regard to jurisdictional claims in published maps and institutional affiliations.

Copyright: (C) 2022 by the authors. Licensee MDPI, Basel, Switzerland. This article is an open access article distributed under the terms and conditions of the Creative Commons Attribution (CC BY) license (https:// creativecommons.org/licenses/by/ $4.0 /$ )
College of Aerospace Science and Engineering, National University of Defense Technology, Changsha 410073, China; xiexiong1997@163.com (X.X.); heliang09@nudt.edu.cn (L.H.)

* Correspondence: shengtao-2002@163.com

\section{Text Correction}

We, the authors, wish to make the following corrections to our paper [1]. We have found that Equations (29) and (32) and $\psi$ were stated incorrectly in the manuscript. We forgot to add parentheses when deriving the derivative of $\widetilde{\chi}_{i}$, which led to these errors in the paper.

Equations (29) and (32) should be revised as follows:

$$
\begin{aligned}
& \begin{aligned}
\frac{d\left\|\tilde{\chi}_{i}\right\|}{d t} \leq\left\|\dot{\omega}_{e i}+r\left[\sum_{j=1}^{n} a_{i j}\left(\dot{\sigma}_{i}-\dot{\sigma}_{j}\right)+\dot{\sigma}_{e i}\right]\right\| & \\
\leq\left\|\dot{\omega}_{i}\right\|+\left\|\dot{\omega}_{d}\right\| & +n r\left\|\dot{\sigma}_{i}\right\|+n r\left\|\dot{\sigma}_{j}\right\|+r\left\|\dot{\sigma}_{i}\right\|+r\left\|\dot{\sigma}_{d}\right\| \\
\leq 2(n+1) r \delta_{1}+2 \delta_{2} &
\end{aligned} \\
& \frac{d\left\|\tilde{\chi}_{i}\right\|}{d t}+\frac{d\left\|\dot{\tilde{e}}_{i}\right\|}{d t}+\frac{d\left\|\tilde{\eta}_{i}\right\|}{d t} \leq 2(n+1) r \delta_{1}+2 \delta_{2}+2(n+1) \delta_{2}+2\left\|J_{i}\right\| \delta_{1} \delta_{2}+\left\|J_{i}\right\| \delta_{3} \\
& \leq 2(n+1) r \delta_{1}+2(n+2) \delta_{2}+\left(2 \delta_{1} \delta_{2}+\delta_{3}\right) J_{\max }
\end{aligned}
$$

and the variable $\psi$ after Equation (32) should be corrected to the following:

$$
\psi=2(n+1) r \delta_{1}+2(n+2) \delta_{2}+\left(2 \delta_{1} \delta_{2}+\delta_{3}\right) J_{\max }
$$

We also state that this change has no impact on the experimental results. The authors apologize for any inconvenience caused and state that the scientific conclusions are unaffected. The original article has been updated.

\section{Reference}

1. Xie, X.; Sheng, T.; He, L. Distributed Attitude Synchronization for Spacecraft Formation Flying via Event-Triggered Control. Appl. Sci. 2021, 11, 6299. [CrossRef] 